\title{
Particulate Matter in Air and in Liquids - Isolation, Quantitation and Identification Considerations
}

\author{
DS Aldrich, Author
}

Pfizer Global R\&D, MI Pharmaceutical Sciences, Analytical R\&D 7171 Portage Rd. Kalamazoo, MI 49001

Monitoring of ambient air in aseptic fill modules provides an alert to particles in $\geq 0.5$ $\mu \mathrm{m}$ and $\geq 5.0 \mu \mathrm{m}$ thresholds. These limits serve as surrogate predictors of air quality in regard to potential microbiological content. There are defined standards for cleanroom air quality and common means of routine monitoring. The lone 1963 Federal Standard 209 established particle concentration as number of particles/ per $\mathrm{ft}^{3}$. Following an update in 1992 to revision E [1], the standard remained legally in force until 2001 when it was withdrawn. FS 209 early nomenclature is still referenced, but has been replaced by ISO 14644-1 [2]. Particle content in liquid pharmaceutical injectable and ophthalmic products are quantitated against $\geq 25 \mu \mathrm{m}$ and $\geq 10 \mu \mathrm{m}$ thresholds. Two USP compendial methods are suitable to determine the particle load in them, Table $1[3,4]$.

Regardless of the standards or the particle counting method, when an excursion above limit occurs, we have an urgent and difficult analytical project. While monitoring the filling area air and product particle loads is largely an instrumental task, the method to characterize the particles collected is not as simple. Collection of air samples with conductive sticky tape facilitates later examination by electron microscopy and reflected light microscopy. Collection of particles from liquid formulation on filter membranes allows counting and characterization.

In this presentation, collection techniques are discussed that allow subsequent evaluation for chemical speciation and possible identification. We recommend analysis in a stepwise and integrated approach to attain comprehensive material character description. Typical public standards for particle load and the preferred methods are also described including impingement and filter entrainment from air, electronic detection via light obscuration, Figure 1, and membrane filtration via optical microscopy, Figure 2 [5]. Identification of the unknowns is most successful when obtained through the integrated analyses of polarized light microscopy, mid-infrared and Raman spectroscopy and scanning electron microscopy with elemental analysis by EDS [6].

\section{References}

[1] FS 209E, Airborne Particulate Cleanliness Classes in Clean Rooms and Clean Zones, U.S. General Service Administration (1992).

[2] ISO/FDIS 14644-1, Cleanrooms and associated controlled environments-Part 1: Classification of air cleanliness, TC 209 of the Intl Stds Org (1999).

[3] USP 28/NF 23, Chapter $<788>$ "Particulate Matter in Injections", United States Pharmacopeial Convention, Inc. Rockville, MD (2005). 
[4] USP 28/NF 23, Chapter < 789> "Particulate Matter in Ophthalmic Solutions", United States Pharmacopeial Convention, Inc. Rockville, MD (2005).

[5] D.S. Aldrich. The Microscope, 45:3, (1997), 73-83.

[6] D.S. Aldrich and M.A. Smith. Appl. Spec. Rev. 34(4), (1999), 275-327.

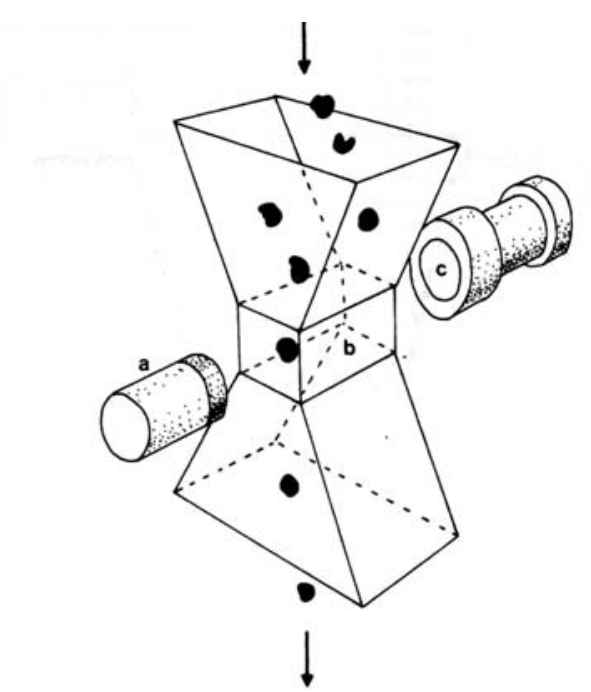

Diagrammatic view of a light obscuration sensor. Key: a-light source; b— sensing zone; $\mathrm{c}-$ detector.

Figure 1. Light Obscuration Detector

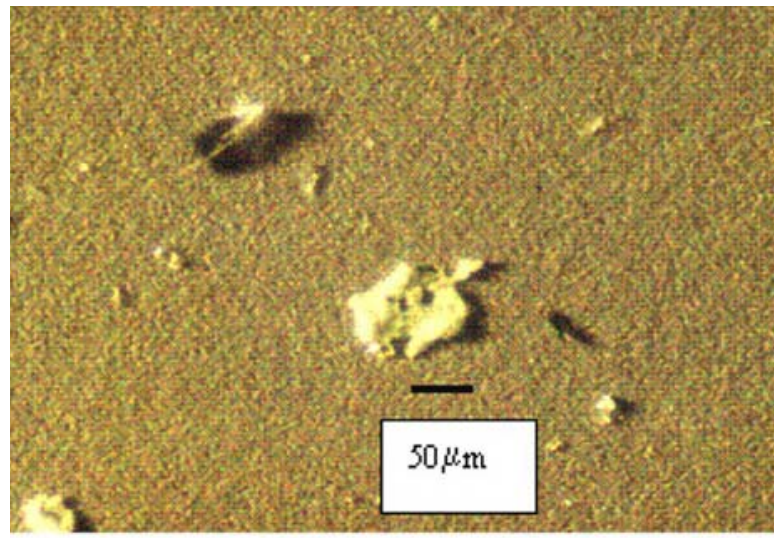

Figure 2. Membrane Microscopic Retention of Particles.

\section{Table 1. U.S. Compendial Limits for Pharmaceutical Liquid Formulations}

\begin{tabular}{|c|c|c|c|c|c|c|c|}
\hline \multirow[t]{3}{*}{ Assay } & \multirow{2}{*}{\multicolumn{2}{|c|}{$\begin{array}{c}\text { Injectable Small } \\
\text { Volume Products } \\
\leq 100 \mathrm{~mL} \\
\begin{array}{c}\text { Particle Limit per } \\
\text { Container }\end{array}\end{array}$}} & \multirow{2}{*}{\multicolumn{2}{|c|}{$\begin{array}{c}\begin{array}{c}\text { Injectable Large } \\
\text { Volume Products } \\
>100 \mathrm{~mL}\end{array} \\
\text { Particle Limit per mL }\end{array}$}} & \multicolumn{3}{|c|}{ All Ophthalmic Products } \\
\hline & & & & & \multicolumn{3}{|c|}{ Particle Limit per $\mathrm{mL}$} \\
\hline & $\geq 10 \mu \mathrm{m}$ & $\geq 25 \mu \mathrm{m}$ & $\geq 10 \mu \mathrm{m}$ & $\geq 25 \mu \mathrm{m}$ & $\geq 10 \mu \mathrm{m}$ & $\geq 25 \mu \mathrm{m}$ & $\geq 50 \mu \mathrm{m}$ \\
\hline $\begin{array}{c}\text { Light } \\
\text { Obscuration }\end{array}$ & 6000 & 600 & 25 & 3 & 50 & 5 & Not Stated \\
\hline $\begin{array}{l}\text { Membrane } \\
\text { Microscopic }\end{array}$ & 3000 & 300 & 12 & 2 & 50 & 5 & 2 \\
\hline \multicolumn{8}{|c|}{ Membrane Assay } \\
\hline $\begin{array}{c}\text { Per mL for } \\
5 \mathrm{~mL} \mathrm{Vol}\end{array}$ & 600 & 60 & & & & & \\
\hline $\begin{array}{l}\text { Per mL for } \\
25 \mathrm{~mL} \mathrm{Vol}\end{array}$ & 120 & 12 & & & & & \\
\hline $\begin{array}{l}\text { Per mL for } \\
\text { Vol } 50 \mathrm{~mL}\end{array}$ & 60 & 6 & & & & & \\
\hline $\begin{array}{l}\text { Per mL for } \\
100 \mathrm{~mL} \mathrm{Vol}\end{array}$ & 30 & 3 & & & & & \\
\hline
\end{tabular}

